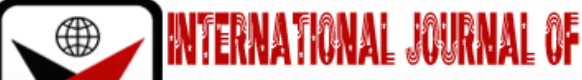

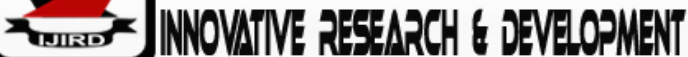

ISSN 2278-0211 (Online)

\section{Language and Technology: Nigeria's Digital Discourse Analysis}

\author{
Doutimiebi Simon \\ Lecturer, Department of General Studies, \\ International Institute of Tourism and Hospitality, Yenegoa, Bayelsa State, Nigeria \\ Chinwe Godwin Udom \\ Lecturer, Department of General Studies, \\ Captain Elechi Amadi Polytechnic, Rumuola, Port Harcourt, Nigeria
}

\begin{abstract}
:
This paper scrutinizes the language of digital discourse in Nigeria. Digital discourse analysis is concerned with how multimodal, multisemiotic resources are employed to enact identities, activities and ideologies in the digital world, as part of a larger social world. Data for this study comprised of 130 online posts collected from This Day Newspaper and Daily Trust NewspaperFacebook pages. Data was collected between August and September 2020 to extract the political comments of forum members before and after the gubernational election in Edo state. The data were analysed using the sociolinguistic and discourse methods alongside Fairclough's Critical Discourse Analysis (CDA) and Halliday's Systemic Functional Grammar (SFG) as the theoretical models. Findings reveal that digital discourse in Nigeria is distinguished by attributes of two English variants: Nigerian English and internet English. Loan words and culture-specific speech habits are recognized to be in the enclave of Nigerian English whilst shortening devices and instances of verbal language are within the sphere of internet English.
\end{abstract}

Keywords: Language, digital discourse, Nigerian English, internet language, social change

\section{Introduction}

Human language conforms both to the sociolinguistic environment of its users and to the application of tools which facilitate its usage. The pliability of language is partially hinged on the distinct linguistic needs and the culture of the people in a given society. The advent of technological tools, such as the printing press in 1440 by Johannes Gutenberg which transformed the production of books (Eisenstein, 1983) and the invention of the computer energized the reading and writing culture, as well as human communication (Mahoney, 1998). The incorporation of technology into everyday linguistic communication has supported and advanced the utilization of language. Presently, ICT has become a mainstay in communication to the extent that people naturally communicate with digital tools but show less concern on the technological tools that makes it possible (Jung, 2006). The emergence of digital technology has enriched and expanded the scope of communication and brought about an increase in the use of language especially in its written electronic form using relevant digital communication channels (Crystal, 2004). Social Media platforms including Facebook, Twitter, WhatsApp among others have enabled the online community to interact amongst themselves, which has culminated in the concept - digital discourse.

Even though ICT has improved and broadened the use of language, its role has also raised pertinent issues on the negative effect ICT may have on language (Onadeko, 2011). Such issues encapsulate the prospects of technology facilitating the aberration of grammatical usage and principles in the form of short codes development, respelling etc. Conversely, Androupoulos (2011) submits that the new digital media should not be conceived to bea language usage determinant but rather as an invaluable tool for social interaction, which does constrain but does not determine the shapes and styles of network writing. He further averred that the linguistic activities can be perceived as a process of change facilitated and enabled by digital media, but actualized and performed by networked writers'( $p$. 13). The choice of the written forms is thus the making of the language user and not that of the technology that facilitates interactions. Nigerians, especially the youths engage actively in digital discussions ranging from current socio-political issues to environmental, religious and economic issues. There are two dimensions in which digital discourse is used in this paper. First one refers to the written discussions on internet platforms and the other refers to the analysis of electronically written texts generated in the course of online discussions, aided by digital technology. The language of digital discourse in Nigeria is English. English is the official lingua franca of Nigeria and is noted for other peculiar features which differentiate it from other Nigerian indigenous languages. 


\section{Nigerian English and Digital Discourse}

Several characteristics distinguish the English language in Nigeria from other indigenous language options, due to the conditioning English has been subjected to in Nigeria. This conditioning is what scholars termed as'nativisation' or 'domestication' (Bamgbose, 1995; Adegbija, 2004). While some of these attributes are phonological (such as the replacement of $/ \theta /$ with $/ t /$ ), others are lexical, pragmatic or grammatical (e.g., sorry, well done, thank you for yesterday, etc.). Hallmarks of Nigerian English also comprises the creative formulation of words and expressions (e.g., take in - get pregnant), as well as the translation of some culture-specific linguistic dispositions of Nigerians into English. For example, 'I am dumbfounded' can be communicated in Igbo speech habit as 'I don't have the mouth with which to tell you'. Bamgbose (1995) also recognizes the assimilation of Americanisms such as the use of vacation (American) instead of holiday (British). Presently, Nigerians communicate regularly via digital platforms and given that English is the unifying language in Nigeria, the conjecture is that Nigerian English hallmarks will be conspicuous in the Nigerian digital discourse. Extant literature works on digital language are sufficient enough to glean relevant information on the subject matter. For instance, the work of Paolilio (2001) conceives digital language as a new and different language variety that is strongly affiliated with the existing language. Digital language also connotes the linguistic features of slangs (Nazaryan\&Gridchin, 2006), and has equally been identified as a style stemming from the linguistic activities of the online community which is enabled by digital media (Androupoulos, 2006). Sufficient thoughts have equally been given to the distinct morphological process of internet language which is a departure from the conventional norm (Crystal, 2004; Sun, 2010), and to the issue of language preponderance on the internet, which Posteguillo (2002) argued has been dominated by English which has become the internet's lingua franca. The characteristics of internet language have led to its study under the Netlinguistics framework (Posteguillo, 2003), or the internet linguistics subfield (Crystal, 2005 \& 2011). Scholarly consideration on Nigerian internet language has revealed that Nigerian email construct has evidence of Nigerian English features (Chiluwa, 2010a and 2010b), as well as features of West African English (Chiluwa, 2013). Instant message and short message service also share a likeness in structure (Oni, 2011), while Onadeko, (2011) underscored that Chatroom talk has education implication on English. Language use on the internet by terrorists and extremist is also perceived as a weapon of intimidation and a strategy to mainstream their views and give legitimacy to their terrorist campaigns (Mbarachi, 2013). However, extant studies have not examined the sociolinguistic, technological and discourse perspectives of Nigerian digital discourse. This paper examines the Nigerian digital discourse on topical issues on digital platforms. The study also crossexamines how Nigeria's digital discourse reflects and gauges the mood of Nigerians as expressed in their language. Mood is used here in the context of social change concerning thepolitical, environmental, social and economic state of Nigeria and their respective effect on citizens. Both the sociolinguistic and discourse analysis approach are applied in this study.

\section{Theoretical Background}

Critical Discourse Analysis (CDA) proposed by Norman Fairclough and Systemic functional grammar by Michael Halliday were the theories adopted for this study. According to Dianna (2018), CDA is a qualitative analytical approach for critically describing, interpreting, and explaining how discourses construct, maintain, and validates social inequalities. CDA recognizes that the use of language is purposeful, regardless of whether discursive choices are conscious or unconscious.

This theory aims at extracting the linguistic, semiotic and 'inter-discursive' features of texts which represent a part of social change process such that the textual analysis is integrated into multidisciplinary research on change (Fairclough 2016, p. 453). Texts collected as data are considered part of discursive events but in textual forms. The linguistic analysis of texts includes the interdiscursive analysis which incorporates elements of -context into the text to show the relationship between concrete occasional events and more durable social practice. This allows one to connect the linguistic hallmarks with the process of social change. Social change is used here to refer to change in social practice which using the Nigerian example may represent the change in government, the fight against corruption, politics, etc. It also includes the use of the digital media by the citizenry for discursive events which conceptualizes their response to the social change. CDA is applied in this study as a tool for determining how the linguistic features of digital discourse of Nigerians relate to the social, cultural and political contexts/meanings intended by discourse participants in the context of social change.

Halliday's systemic functional grammar is also applied in this study. According to this theory, language is primarily a resource for making meaning in context (Halliday 2014, p. 3). Language is a system of systems and a system of choice and meaning, used for interaction and construction of interpersonal relations and social order (Halliday, 1997). Language is also viewed as a tool for representing knowledge and constructing meaning. The theory views language as functional and divides it into three meta functions: the ideational, interpersonal and textual meta functions.

The ideational meta function deals with the construction of experience through language which the speaker (or writer) expresses as ideas in form of the subject of discourse. The Interpersonal meta function refers to the participants in a discourse or interaction, and the relationship that exists between or among them. This relationship determines the linguistic choices made by the speaker in the discourse. Whilst the textual meta function of language complements the ideational and interpersonal meta functions by creating relevance (Daramola 2005, p. 69). The textual meta function creates the text (whether spoken or written), as well as relate the textual construct to the context of the situation. This model is used to account for the context of meaning in the subjects' discursive events with social change.

\section{Methodology}

Data for the study comprises posts collected from the Facebook pages of two premium Nigerian newspapers (This Day and Daily Trust). The data were comments posted between August and September 2020 by forum members in reaction to topical news items on the two online newspapers. Two hundred written texts were used for the study (One 
hundred from each of the two online newspapers). Posts relating to politics, the state of the economy and the fight against corruption were selected as appropriate reactions from registered forum members/readers who made contributions. These data were analysed using sociolinguistic and discourse approaches. Owing to the limited space, all the texts are not sampled in the analysis in this paper. The sampled texts are coded T1, T2, etc., where T stands for 'texts', while numbers are used to identify the given texts being referred to. The reason is for the reader to see their intended meaning.

\section{Findings and Discussion}

\subsection{Nigerian English Features}

\subsubsection{Code-Switching and Mixing}

The data contains features of code-mixing and code-switching. These features are discussed below.

- T1: No! the people's vote has the final say. INEC is just an umpire. The point is the evil axis can never prevail with their lies, innuendoes and campaign of calumny. Yeye de smell.(sic)

- T2: ...the stage may be set for rigging in favour of Pastor Izeyamu, but who knows how the pendulum will swing, the answer comes in less than a week. SaiObaseki. (sic)

- $\quad$ T31: Onyeiberibe, does one have to reap from a government? Characters like you get it all wrong... (sic)

- T33: Anumpama. Tribalistic bigot (sic)

- T47: I tire o...People who got d means n visa must travel out when they want, pple who dnt, will always bark like dogs, poor pple...They shld use Morocco like others $n$ drown $n \mathrm{~d}$ med. seaabeg(sic)

- $\quad$ T89: All those Oshiomoleapologies go don kpeme with envy now! Obagolddey shine!(sic)

- T93: Bad belle. Go hang. Rest in peace in advance! (sic)

The sampled texts above show incidences of code-switching from English language to other indigenous languages in Nigeria, pidgin inclusive. Code-switching and code-mixing are sociolinguistic terms that refer to the appropriation of language that draws from two or more languages and combines the codes in different ways. A code may be a word, language or a variety or style of a language. The term codemixing underscores hybridization, while codeswitching connotes the movement from one language to another (McArthur, 1998). Yeye de smell in T1 is a pidgin expression. The origin of this expression is traceable to the lyrics of one of the songs by the late afro-beat singer FelaAnikulapoKuti. Yeye means foolish or foolishness. "Smell" is an English word which means to perceive with the nose. But in its Pidgin context, smell has a negative connotation and means something that has a foul odour. In T1, "yeye de smell" shows how disgusting and repulsive it is to do something bad such as rigging election or playing politics fraudulently as implied by T1 above. The writer code switches from English to this pidgin expression in order to give the cultural context of his disgust for electoral malpractice, a feeling that he may not have appropriately expressed in English."SaiObaseki" in T2 means 'Only Obaseki' in Hausa language. Obaseki is the current Governor of Edo State who won a second election bid under the platform of the People Democratic Party (PDP). The travails he suffered prior to his reelection as Edo state Governor including the squabbles between him and erstwhile national chairman of the All-Progressive Congress (APC) forced him to jettison the APC for the PDP. Many supporters of the governor were always chanting "SaiObaseki"in support of his candidature. This slogan was first used and popularized by the campaign that brought President MuhammaduBuhari in 2015. In T31, "onyeiberibe" literarily means a foolish person. This is an abusive expression in Igbo. In its cultural context, it means "one who is worthless or a stupid person". In T47 "I tire o" is a pidgin expression which literarily means 'I am tired'. But the cultural context of this expression in the text does not mean "tired"; rather it means "I am surprised" usually expressed when something surprising is said or happens. "Abeg" in the same T47 is also a pidgin word which means "please". It has different contexts. In one context, it can effectively function as 'please' but in this context, its meaning is more of 'excuse me' said sarcastically. T89 and T93 also contain pidgin code switched and mixed expressions. For instance,"go don kpeme" in T89 is a pidgin expression which means must have died in English. 'Baba de shine' means anything from Baba is living well, is popular or is winning. 'Bad belle' in T93 means a jealous person who does not wish others good. These codeswitched and mixed expressions were used by the forum text writers to culturally express the views which they would not have adequately expressed in English. This Nigerian English feature in digital discourse also underscores the sociolinguistic reality of the Nigerian situation where many languages are spoken in addition to English and pidgin.

Loan Words: Due to the multilingual nature of the Nigerian sociolinguistic environment, loan words are common attributes of digital discourse English in Nigeria. The following table contains the loan words found in the data.

\begin{tabular}{|c|c|c|}
\hline Loan Words & Source Language & Meaning \\
\hline oga & Yoruba & right \\
\hline abi & Yoruba & Locally made gin \\
\hline ogogoro & Yoruba & Kings \\
\hline obas & Yoruba & Islamic scholar \\
\hline mallams & Arabic & Fool, a stupid person \\
\hline mumu & Igbo & wow \\
\hline Allah & Arabic & fool \\
\hline Chai & Igbo/Yoruba & Igbo \\
\hline Anumpama & Worod & \\
\hline
\end{tabular}

Table 1: Loan Words in Digital Discourse 
Table 1 shows the loan words identified in the study data. The words have become part of Nigerian English discourse that many people do not bother about their source as their meaning is generally known. For instance, 'oga' is a pidgin word for master or boss. It is a Yoruba word which has been adopted in pidgin. 'Abi' is also of Yoruba origin. It is an interrogative word which means different but related things depending on the context in which it is used. It can mean 'right?' or 'isn't it?' It can also mean 'or' and 'yes'. 'Ogogoro' is also a Yoruba word which is translated to local gin. Other names used for this gin are 'Sapele water', 'kparaga', 'kai-kai', 'push-me-I-push-you', 'akpuruachia', etc. Due to the strategic nature and location of Lagos which hosts many people from all the ethnic groups in Nigeria, and which is also a state in the South West - a Yoruba region, 'ogogoro' is the most popular of the names given to this local gin. The subjects' preference for these loan words is to capture the cultural meanings in their discourse instead of using the English equivalents devoid of such intended cultural meaning of the words. For instance, the use of 'dry gin' instead of 'ogogoro', is contextual as the Nigerian reader does not need any explanation on the word 'ogogoro'. The following post illustrates:

- T65:I think Oshiopikin is a shameless man after ruining our economy u still hv mouth, don't u know that u are the most corrupt governor and party chairman. By now you're supposed to be in jail with your ogogoro.

'Ogogoro' is used here instead of dry ginand the assumption is that 'ogogoro' will be a source of consolation to the erstwhile national APC chairman if jailed for corruption. 'Ogogoro' sometimes implies drunkenness in the Nigerian context. One who drinks a lot of it may end up messing things up because of its high alcoholic content. 'Oba' is the Yoruba name for a king. As for 'Mallam', the root word comes from the Arabic word 'alim' or 'muallim' which means a Muslim, learned in religious matters. 'Mumu' is an Igbo word translated a dullard in English language. 'Allah' is the Arabic word translated God and requires no further explanation. 'AnuMpama' (foolish animal) is an Igbo phrase that means a worthless person in English. These words were loaned into Nigerian English by the interlocutors in their digital discourse as part of the domestication of internet English.

\subsubsection{Translation Equivalents}

This refers to the transfer of Nigerian indigenous language habits into English. For instance, 'go and have seat' (T62) and 'u still hv mouth' (T65). Go and have seat is another insulting way of saying - go and sit down. The expressiondoes not require the addressee to sit down but is another way of dismissing the person or precluding him/her from partaking in a conversation either due to disgusting social attitude of the person or because the person is inexperienced on the discourse theme. ' $U$ still hv mouth', is an expression that means the speaker should keep quiet. This expression is used when someone has misbehaved or done something wrong, yet, claims that he is right or argues in his favour even when it is glaring that he is wrong. It is a subtle way of saying that the person should shut up and perhaps plead for mercy instead of provoking those he/she offended.

\subsubsection{Nigerian English Phonology}

Two features of Nigerian English phonology were observed. The first one is anti 'kwaraptian' master (T62) and the second is May Allah 'helf' u baba(T80). Both 'Kwaraptian' and 'helf' are allusions to the common feature of Hausa subvariety of Nigerian English. The writers replaced /k/ consonant sound with / kw/, and the vowel sound /ə/ with /æ/ in the realization of the word's corruption and the replacement of /p/ with /f/ in help, both of which are common hallmarks of the phonology of Hausa English bilinguals.

\subsection{Internet English Features}

The structure of Nigerian digital English has an amalgamationof letter homophones and shortening devices. These include such short forms as 'becos', 'bcos' - because; 'dnt' - do not or don't; 'whts' - what is; 'u' - you, etc. (see T48). Others include the use of initials, for instance, GEJ - GoodluckEbele Jonathan, PMB - President Mohammad Buhari, OBJ Obasanjo. These initials may have variants with lower case letters as well. Acronyms such as INEC were also found. Most of these initials refer to names known to many Nigerians. Another internet English characteristics found in the data is the presence of spoken mode features which makes the texts appear as if the subjects were talking. Examples include 'sharrap!!!' (T48); 'shurupur mouth there' (T77); 'sooooooo....' (T14); 'I tire o...' (T47), 'u still hv mouth' in (T65), etc. These examples imply that the writers and their referents are engaged in a verbal conversation hence a spoken mode feature of digital discourse.

\section{Conclusion}

This study has shown that Nigerian digital discourse is characterized by a combination of the linguistic features of Nigerian English and internet language. The use of loan words, code-switching/mixing, as well as some culture-specific speech habits of Nigerians is evidence of its Nigerian English feature content. The use of shortening devices and instances of verbal language in the posts shows its relationship with internet language also. Digital discourse in Nigeria reflects an emerging social internet culture with freedom of expression and anonymity of forum members whose posts deemphasized their interpersonal relationship with that of their referents. As a result, the application of the interpersonal meta function of the systemic model in the analysis of online texts with anonymous identities is challenged. Evidence of the use of abusive and uncivilized language in Nigerian digital discourse was found. Besides, digital discourse in Nigeria (concerning social change) reflects an ethnic and political polarization of Nigerians with more divisive than uniting tendencies. This trend portends danger if unchecked as language should be positively employed in the unification of all Nigerians. In summary, the researcher recommends strict monitoring and censoring of unwholesome, vulgar and abusive posts by the operators of such Nigerian internet forums sites, especially the posts with ethnic, political and religious coloration which have divisive tendencies. 


\section{References}

i. Adegbija, E. (2004). The domestication of English language in Nigeria. In S. Awonusi\& E. A. Babalola (Eds.), The domestication of English in Nigeria. (pp. 20 - 44). University of Lagos Press.

ii. Androutpoulos, J. (2006). Introduction: sociolinguistics and computer-mediated communication. Journal of sociolinguistics, $10(4), 419-438$.

iii. Androutsopoulos, J. (2011). Language change and digital media: A review of conceptions and evidence. In N. Coupland\& T. Kristiansen (Eds.), Language standardisation in Europe. Retrieved from

http://jannisandroutsopoulos.files.wordpress.com/2011/11/language-change-and-digital-mediapreprint.pdf

iv. Bambgose, A. (1995). English in the Nigerian environment. In A. Bamgbose, A. Banjo \& A. Thomas (Eds.), New Englishes: a West African perspective(pp. 9 - 26).

v. Chiluwa, I. (2010a). Nigerian English in informal email messages. English Worldwide, Vol. $31(1), 40$ - 61

vi. Chiluwa, I. (2010b). Discursive practice and Nigerian identity in personal emails. In Taiwo, R. (Ed.) Handbook of research on discourse behaviour and digital communication: Language structures and social interaction.pp. 112 129, IGI Global Publishers.

vii. Chiluwa, I. (2013). West African English in digital discourse.Covenant Journal of Language Studies, Vol. 1 No. 1 , pp. $42-61$

viii. Crystal, D. (2004). Language and the internet.Cambridge university press.

ix. Crystal, D. (2005). The scope of internet linguistics.Paper given online to the American association for the advancement of science meeting. Retrieved from http://www.davidcrystal.com/DC_articles/Internet2.pdf

x. Crystal, D. (2011). Internet linguistics: A student guide. Cambridge university press

xi. Daramola, A. (2005). Towards an understanding of systemic functional theory (SFT) for teachers of English in Nigerian secondary schools.Journal of the Nigeria English Studies Association, Vol. 11 (1), pp. 65 - 76

xii. Eisenstein, E. (1983). The printing revolution in early modern Europe. Cambridge University Press

xiii. Fairclough, N. (2012). Critical discourse analysis. International scientific researches (ISR), Vol.7, 452 - 487

xiv. Halliday, M. A. K. (2014). Halliday's introduction to functional Grammar.4th edition.Routledge Taylor and Francis Group.

xv. Halliday, M. A. K and Matthiessen, C. (1997). Systemic functional Grammar: a first step into the theory. Available at

http://minerva.ling.mq.edu.au/Resources/VirtuallLibrary?Publ...SFG\%20intro\%20New.htm.

Retrieved 20 September,2020.

xvi. Jung, S. (2006). The use of ICT in learning English as an international language. A doctoral dissertation submitted to the Graduate School of the University of Maryland, College Park

xvii. Mahoney, M. S. (1998). The history of computing in the history of technology. Annals of History of Computing, $10,113-125$

xviii. McArthur, T. (1998).Code-mixing and code-switching.Concise Oxford Companion to the English Language.Oxford University Press

xix. Mbarachi, C. S. (2013). Language and Terrorism: an analysis of select statements of the 'Boko Haram' group. Journal of research in Nigerian English and literature (JONEL), 10, 197 - 212

xx. Nazaryan1, A. \&Gridchin, A. (2006).The influence of internet on language and 'Email stress'. Law and Politics $4(1), 23-27$.

xxi. Onadeko, T. (2011).Chatroom talk and its influence on the acquisition of the English language in Nigeria.Journal of Nigeria English studies 14 (1), 60 - 71.

xxii. Oni, W. (2011). A lexico-semantic analysis of computer-mediated discourse in select instant \&text messages of Nigerian students. In A. Akande\& A. Odebunmi (Eds.), Sociology of English in Nigeria (pp. 39 - 68). Retrieved from

http://www.academia.edu/1938592/A_LexicoSemantic_Analysis_of_ComputerMediated_Discourse_in_Select_I nstant_and_Text_Messages_of_Nigerian_Students

xxiii. Paolilio, J. C. (2001). Language variation on internet relay chat: A social network approach. Journal of sociolinguistics, 5(2), 180-213.

xxiv. Posteguillo, S. (2002).Netlinguistics and English for internet purpose. IBÉRICA 4, 21-38.

xxv. Posteguillo, S. (2003).Netlinguistics: An analytical framework to study language, discourse and ideology in internet. Castello De La Plana: Publicacions de la Universitat de Jaume.

xxvi. Sun, H. (2010).A Study of the features of internet English from the linguistic perspective.Studies in literature and language, 1(7), 98-103. Retrieved from www.cscanada.org 